
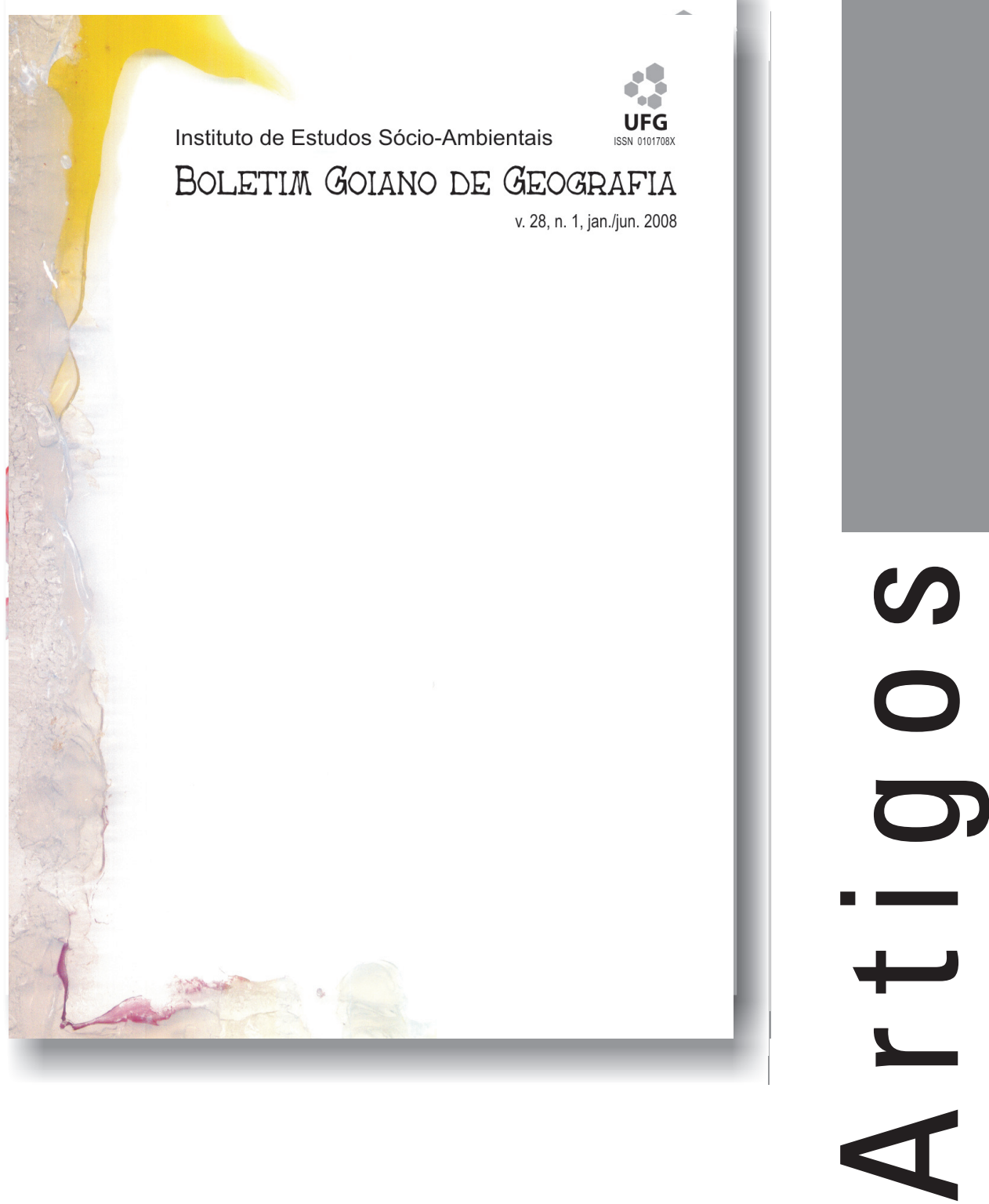


\title{
Diagnóstico Geoambiental da bacia hidrográfica semi-árida do Rio Acaraú: subsídios aos estudos sobre desertificaçãa ${ }^{1}$
}

\author{
Diagnosis Geoambiental of the River Acaraú river basin semi-arid: subsidies to the studies on \\ desertification
}

\author{
Flávio Rodrigues do Nascimento - Universidade Federal Fluminense \\ flaviogeo@bol.com.br \\ Sandra Batista da Cunha - Universidade Federal Fluminense
sandracunha@openlink.com.br \\ Marcos José de Souza - Universidade Estadual do Ceará \\ mestgeo@uece.com \\ Maria Lúcia Brito da Cruz - Universidade Estadual do Ceará \\ mlbc@uece.com.
}

\section{Resumo}

0 presente artigo trata do Diagnóstico Geoambiental da Bacia Hidrográfica semi-árida do Rio Acaraú que abrange parte da porção centro-norte do Estado do Ceará. Portanto, 0 objetivo do trabalho é mostrar a compartimentação geoambiental desta bacia, destacando uma análise ambiental sobre os recursos naturais. Registra-se ainda que a bacia em foco abriga um diversificado mosaico de sistemas ambientais que sofreram expressivas transformações motivadas pelo processo histórico de uso e ocupação da terra. Diante de uma relação conflituosa entre sociedade e natureza nos sertões de clima semi-árido, sobressai na bacia, a desertificação como conseqüência da degradação ambiental.

Palavras-chave: análise geoambiental, bacia hidrográfica e clima semi-árido

\begin{abstract}
The present article treats of the geo- environment diagnosis of Acaraú river basin semi-arid that embraces part of the center-north portion of the State of Ceará. Therefore, the objective of the work is to show the compartimentação geo- environment of this basin, detaching an environmental analysis on the natural resources. Enroll although the basin in focus shelters a diversified mosaic of environmental systems that suffered expressive transformations motivated by the historical process of use and occupation of the earth. Due to a conflicting relationship among society and nature in the interiors of semi-arid climate, it stands out in the basin the desertification as a consequence of the environmental degradation.
\end{abstract}

Key-words: geo-environment diagnosis, river basin and semi-arid climate

\begin{tabular}{|l|c|c|c|c|c|c|}
\hline Boletim Goiano de Geografia & Goiânia - Goiás - Brasil & v. 28 & n. 1 & p. 41-62 & jan. / jun. & 2008 \\
\hline
\end{tabular}




\section{Introdução}

Este artigo trata do Diagnóstico Geoambiental da Bacia Hidrográfica do Rio Acaraú - Estado do Ceará (Figura 01). As bacias em foco abrigam um diversificado mosaico de sistemas ambientais que sofreram agudas transformações motivadas pelo processo histórico de uso e ocupação da terra.

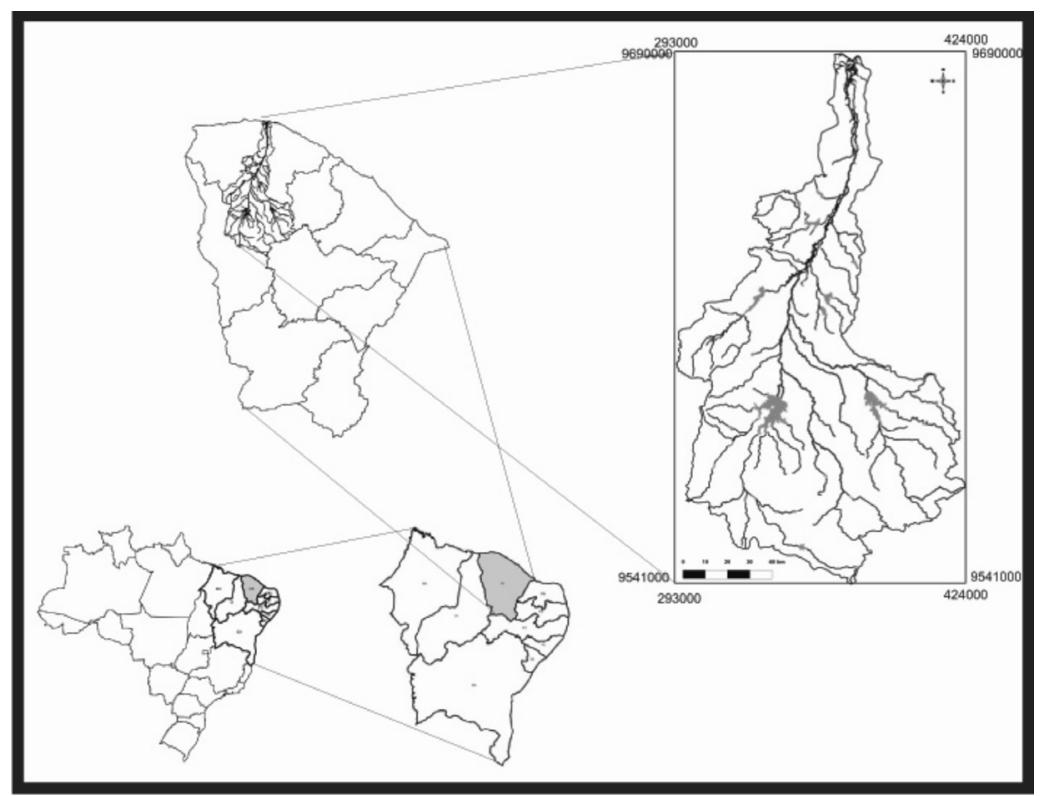

Figura 1 - Bacia Hidrográfica do rio Acaraú, Centro-Norte do Estado do Ceará/Nordeste do Brasil

Os sistemas ambientais da bacia tendem a apresentar um arranjo espacial decorrente da similaridade de relações entre os componentes naturais - de naturezas geológica, geomorfológica, hidroclimática, pedológica e bioecológica - materializando-se nos diferentes padrões de paisagens. Considera-se que os sistemas ambientais (geossistemas) são integrados por variados elementos que mantêm relações mútuas entre si e são continuamente submetidos aos fluxos de matéria e de energia. Cada sistema representa uma unidade de organização do ambiente natural. Em cada sistema verifica-se, comumente, um relacionamento harmônico entre seus componentes, e eles são dotados de potencialidades e limitações específicas sob o ponto de vista 
dos recursos ambientais. Como tal, reagem também de forma singular no que tange às condições históricas de uso e ocupação.

Considerando os pressupostos retromencionados, o estudo das bacias busca atingir os objetivos delineados a seguir:

- Identificar e caracterizar as principais variáveis ambientais relativas ao suporte (condições geológicas, geomorfológicas e hidrogeológicas), ao envoltório (clima e hidrologia de superfície) e à cobertura (solos e condições de biodiversidade);

- Elaborar o diagnóstico ambiental do meio físico-biótico com base na aplicação de metodologia sistêmica;

- Delimitar os sistemas ambientais com base nas relações entre os componentes abióticos e bióticos de cada sistema;

- Utilizar produtos de sensoriamento remoto na elaboração da cartografia temática das áreas de influência da bacia em escala compatível com os objetivos do projeto;

- Indicar as potencialidades, as limitações e a ecodinâmica dos sistemas ambientais, definindo sua capacidade de suporte;

- Identificar impactos que têm afetado os sistemas ambientais.

Estratégias metodológicas com fins ao diagnóstico e à compartimentação geoambiental

O diagnóstico geoambiental envolvendo a caracterização da área da bacia do rio Acaraú, considerou como estratégias metodológicas as seguintes: abordagem sistêmica; valorização da multidisciplinaridade; e sistema de informação. A abordagem sistêmica considera o sistema como o conjunto de unidades que têm relações entre si. O conjunto significa que "as unidades possuem propriedades comuns, sendo que o estado de cada unidade é controlado, condicionado ou dependente do estado das demais unidades". Acrescenta-se que "os sistemas não atuam de modo isolado, mas funcionam dentro de um ambiente e fazem parte de um conjunto maior" (MMA, 2001.14). Sob o ponto de vista teórico-metodológico a abordagem sistêmica integra o conjunto das variáveis ambientais envolvidas no processo.

A valorização da multidisciplinaridade foi indispensável, diante do espectro amplo de atividades e estudos envolvidos no programa. Desse modo, o estudo geoambiental demandou um conhecimento profundo da realidade físico-natural da área pesquisada. O sistema de informação contemplou os diferentes módulos de coleta, armazenamento, tratamento e divulgação de 
dados, concentrando informações e descentralizando o seu acesso. Não obstante, para a elaboração do Diagnóstico Geoambiental, os estudos consideram o contexto das variáveis físicas e bióticas. Foram interpretadas, também, as relações entre os subsistemas naturais e as condições do uso e ocupação que encerram a realidade estática e dinâmica do espaço. Foram obtidas informações integradas em uma base geográfica, de modo a classificar o território de acordo com a sua capacidade de suporte. Na elaboração do Diagnóstico Geoambiental as análises setoriais serviram de meio para a integração dos componentes. Adotou-se procedimentos que conduzem à delimitação dos sistemas ambientais, em consonância com pressupostos metodológicos integrativos capazes de apreender as relações de interdependência entre os componentes físico-bióticos.

Os sistemas ambientais foram hierarquizados e discutidos em escala compatível com base na interpretação de imagens orbitais e com rigoroso controle de campo. As análises temáticas demonstraram o estreito relacionamento mútuo entre os componentes geoambientais. Estas análises, que encerram a primeira etapa do diagnóstico, foram conduzidas de modo a definir as características das diversas variáveis que compõem o meio físico. Seqüencialmente, foram apresentadas as condições lito-estratigráficas e as características das feições morfogenéticas; características climáticas e hidrológicas; distribuição dos solos, suas principais propriedades e os padrões de cobertura vegetal. Essa seqüência apresentou uma cadeia de produtos parciais que expôs uma relação de dependência entre as variáveis geoambientais. Cada uma delas apóia-se nas anteriores e fundamenta as seguintes.

As unidades Geossistêmicas foram delimitadas em função de combinações mútuas específicas entre as variáveis geoambientais. Destacando-se as diversidades internas dos geossistemas são delimitadas as unidades elementares (geofácies) contidas em um mesmo sistema de relações. Sob esse aspecto, a concepção de paisagem assume significado para delimitar as subunidades, em função da exposição de padrões uniformes ou relativamente homogêneos. A paisagem encerra o resultado da combinação dinâmica e instável de elementos físicos, biológicos e socioeconômicos que, reagindo dialeticamente uns sobre os outros, fazem dessa paisagem um conjunto único e indissociável em perpétua evolução (Bertrand, 1969).

Os sistemas ambientais tendem a apresentar um arranjo espacial decorrente da similaridade de relações entre os componentes naturais - de naturezas geológica, geomorfológica, hidroclimática, pedológica e bioecológica - materializando-se nos diferentes padrões de paisagens. Considera-se que 
os sistemas ambientais (geossistemas) são integrados por variados elementos que mantêm relações mútuas entre si e são continuamente submetidos aos fluxos de matéria e de energia. Cada sistema representa uma unidade de organização do ambiente natural. Em cada sistema verifica-se, comumente, um relacionamento harmônico entre seus componentes e eles são dotados de potencialidades e limitações específicas sob o ponto de vista dos recursos ambientais. Como tal, reagem também de forma singular no que tange às condições históricas de uso e ocupação.

A síntese das unidades geossistêmicas está apresentada através de quadros que contêm informações sobre a denominação das unidades e sobre as características predominantes das condições geoambientais: geologia, geomorfologia, hidroclimatologia, solos e vegetação. Estas servem de base para indicar condições potenciais ou limitativas, quanto às possibilidades de uso dos recursos naturais e das reservas ambientais.

Com o objetivo de avaliar a dinâmica ambiental e o estado de evolução dos sistemas ambientais, foram estabelecidas categorias de meios ecodinâmicos, com base em critérios de Tricart (1977). Cada categoria de meio estável, transição ou intergrades ou fortemente instáveis está associada ao comportamento e à vulnerabilidade das condições geoambientais em função dos processos degradacionais em razão da pedogênese ou morfogênese. Com o enquadramento dos sistemas ambientais em uma determinada categoria de meio ecodinâmico, viabiliza-se a possibilidade de detectar o grau de vulnerabilidade do ambiente e sua sustentabilidade futura: tendencial e desejada.

\section{Configuração geográfica da bacia}

O espaço fisiográfico e ecológico da bacia do rio Acaraú, depende de combinações bastante variadas entre os fatores naturais relacionadas aos rigores do clima semi-árido. Nesse particular, as condições geomorfológicas e climáticas assumem destaca-se na imposição de ambientes dotados de diferentes características, limitações ao uso e potencialidades.

Tratando-se de área submetida em grande parte aos efeitos da irregularidade pluviométrica, aos excessos ou à falta quase absoluta de chuvas, tais condições se exercem sobre os vastos aplainamentos deprimidos do sertão. Assim é que, apesar da posição sub-equatorial, as condições climáticas referidas têm para o território em estudo, efeitos destacáveis sobre os demais 
componentes do potencial ecológico e, consequentemente, sobre a exploração biológica. Os processos morfogenéticos são, em primazia, de natureza mecânica; a drenagem superficial é constituída por cursos d'água dotados de intermitência sazonal; os solos apresentam espessuras ínfimas, com grande freqüência de chãos pedregosos; as disponibilidades de água no solo são deficitárias na maior parte do ano.

Desse quadro genérico sobressai-se o fator que melhor exprime a ecologia regional. Trata-se do recobrimento vegetal das caatingas, cuja fisionomia e flora têm também estreita dependência das propriedades edáficas. Em função do repouso vegetativo à estiagem prolongada, que representa a principal adaptação fisiológica das plantas da caatinga, as espécies perdem a folhagem, configurando uma paisagem peculiar do sertão. É certo porém que, o porte, a densidade, a freqüência de determinadas espécies vão se diferenciando à medida que os solos apresentam condições morfológicas e físico-químicas diferentes. Solos como os Argilosos e Luvissolos tinham, via de regra, um recobrimento de caatinga arbórea densa e com maior riqueza florística. Os Planossolos e Neossolos Litólicos, por outro lado, são revestidos por caatinga arbustiva esparsa com tapete herbáceo constituído de gramíneas.

Contribuindo para diversificar o quadro fisiográfico e ecológico do sertão semi-árido, destacam-se os largos setores de planícies fluviais com Neossolos Flúvicos. Dentre estes, merecem maiores referências as planícies formadas pelos rios intermitentes sazonais do Acaraú, além de alguns tributários com os rios Groíras, Jaibaras e Macacos. A marca característica das planícies é o recobrimento vegetal ribeirinho, com o aspecto de mata ciliar, onde a carnaúba tende a se destacar como espécie dominante.

As serras cristalinas representam as outras porções de diversificação regional. É o relevo colocando-se como elemento diferenciador do clima. Compartimentos de relevo como as serras de Meruoca-Rosário, e das Matas são sujeitas a chuvas mais abundantes e regulares e têm solos com boa fertilidade, com destaque para os Argilosos Eutróficos dos maciços cristalinos. Com isso, o revestimento vegetal primário assume feições contrastantes com o que se assinalou para as depressões sertanejas. Refere-se aos "enclaves" de matas dotadas de indivíduos de elevado porte e grande densidade. Por se tratar de setores do espaço cujas potencialidades ecológicas são mais favoráveis à utilização agrícola, as serras têm apresentado problemas gravíssimos de conservação. Através de um desmatamento indiscriminado e da adoção de técnicas rudimentares, as serras vão pouco a pouco, sofrendo os efeitos dos processos acelerados de erosão cuja tendência é torná-las irreversivelmente improdutivas. 
As áreas pré-litorâneas e costeiras complementam o quadro físicoecológico e enfatizam a impossibilidade de considerar o território abrangido pela bacia do Acaraú como detentora de uma homogeneidade natural. A faixa costeira é marcada pela ocorrência de campos de dunas móveis e fixas, seccionadas pela planície flúvio-marinha recoberta por manguezais. A cerca de $5-10 \mathrm{~km}$ do mar, desenvolvem-se os baixos tabuleiros fracamente sulcados pela drenagem, com coberturas arenosas espessas e revestidos por uma vegetação de médio porte e elevada e densidade.

\section{Uso/ocupação da terra e problemas da degradação ambiental}

As formas de uso e ocupação da terra resguardam relação direta com as políticas de organização do espaço regional por meio das ações dos tomadores de decisão política, de empresários de diversos setores, das Organizações Não-Governamentais e da comunidade civil organizada. A organização do espaço, no que tange ao uso e ocupação da terra, usualmente, produz efeitos ambientais, traduzidos por problemas de degradação dos recursos naturais, sobretudo os renováveis, produzindo impactos socioambientais das mais variadas etiologias. Isto provoca, por exemplo, a diminuição da qualidade ambiental, que revela relação direta com o estado de conservação da vegetação.

A Bacia do Acaraú apresenta variações paisagísticas, em termos de sistemas ambientais, decorrentes das diversidades das condições naturais e das formas de uso e ocupação da terra. A especulação imobiliária, o desenvolvimento do turismo e da carcinicultura, o crescimento desordenado dos núcleos populacionais, o incremento agroindustrial, o manejo de irrigação nos agropólos - perímetros irrigados - como Araras Norte e Baixo Acaraú, a incorporação de terras para agricultura, desmatamento, ablação dos solos e a desertificação estão entre os principais problemas de degradação ambiental observados. Apresenta domínios naturais correspondentes ao litoral, vales, tabuleiros costeiros, serras e cristas residuais, planalto sedimentar da Ibiapaba, e sertões, constituindo domínios naturais que abrigam atividades econômicas características de sua situação ambiental e inserção na lógica de mercado: pesca, maricultura, turismo e lazer, navegação, agroextrativismo, agricultura, indústria e agroindústria, urbanização, açudagem, etc.

Os ambientais costeiros por representarem áreas edafo-climáticas e hidrológicas de exceção no contexto da bacia, seguidos pelos maciços úmidos 
e subúmidos, que têm melhores condições de recursos naturais meio à semiaridez, são mais procurados pelo capital do circuito superior da economia. Por meio do agro-extrativismo e um sistema rudimentar de desenvolvimento da agricultura, os sertões apresentam avançados estágios de degradação, conseqüentes de um nível cultural e de desenvolvimento societário deficiente. A super-exploração dos recursos naturais através de técnicas muito rudimentares, conduz a um progressivo estado de degradação desses recursos.

É evidente que tais problemas ambientais, em todas classes sociais, são determinados pela dinâmica de reprodução do capitalismo e sua articulação em geral. Não menos importante é a junção estabelecida entre o processo de exploração e acumulação e as formas assumidas espacialmente. As formas de ocupação da terra estão relacionadas aos modelos de exploração dos recursos naturais e ambientais devido ao seu valor econômico e social e às atividades exercidas em determinadas áreas - como agricultura, desenvolvimento urbano, turístico e industrial e implementação de infra-estrutura. Fato é que, tanto os ambientes litorâneos, quanto os reservados ao desenvolvimento agroindustrial, são dotados de recursos naturais que são explorados a partir de um incremento de infra-estrutura básica e hídrica ao participarem da lógica de um mercado cada vez mais globalizado, comprometendo e aviltando a agricultura familiar.

Em sua maior parte, o processo de degradação ambiental no Ceará, e em particular na bacia em foco, ocorre mais pelas intervenções socioeconômicas e culturais do que pelos fatores ambientais e sua dinâmica natural. A não observância de formas conservacionistas no uso e ocupação da terra tende a produzir sérios problemas de deterioração ambiental, pondo em risco a capacidade produtiva dos solos e a qualidade ambiental produzindo ulcerações de caráter irreversível na paisagem. Ademais, a tipologia do uso e ocupação da terra na bacia se concretiza através da ocupação urbana e industrial, dos usos múltiplos dos recursos hídricos e dos agroecossistemas. Estes, aqui e acolá apresentam estágios variados de degradação ambiental, os quais podem ser percebidos em todas as unidades de paisagens.

\section{Problemas de degradação ambiental}

A degradação ambiental é conseqüência do uso indisciplinado dos recursos naturais, contingenciados pelas formas de uso e ocupação da terra, sejam eles renováveis ou não renováveis. As ações indiscriminadas con- 
tribuem para tornar recursos renováveis em não-renováveis, provocando o esgotamento dos solos devido ao grau irreversível dos impactos ambientais face à capacidade de suporte dos geossistemas.

Tomando-se por base as características geoambientais e as intervenções das atividades humanas modificadoras das paisagens, é possível mostrar o grau de modificação das condições ambientais na bacia. Assim, os tensores desencadeadores de problemas ambientais são de ordem natural e/ou socioeconômica provenientes da ocupação e do uso desordenado dos recursos naturais. Foi verificado: uma expansão urbana desordenada, o emprego de técnicas agro-silvo-pastoris inadequadas, mineração clandestina, desmatamentos e queimadas, bem como atividades especificamente praticadas no litoral, como a carcinicultura. Estes problemas geram conseqüências na perda da qualidade ambiental - sobretudo dos recursos naturais renováveis e, conseqüentemente, na qualidade de vida da população. É o que pode ser inferido com a consideração dos principais problemas ambientais verificados, a citar: ocupação de dunas, aterramento do manguezal e degradação das matas ciliares, turismo, problemas provenientes da agropecuária, poluição dos recursos hídricos, desmatamento desenfreado e redução da biodiversidade, industrialização e desertificação.

Com a ocupação de dunas, aterramento do manguezal e degradação das matas ciliares são produzidas novas feições paisagísticas, com desconfiguração e fragmentação dos geossistemas, interferindo no estado de conservação ambiental, exatamente em Áreas de Preservação Permanente (APP). Os processos de urbanização hodiernos vêm intensificando a ocupação dessas APP's com residências, segundas residências e com a agricultura. E até mesmo, são produzidas áreas de risco associadas à ocupação desordenada do solo.

A degradação do manguezal tem causado desequilíbrios no ecossistema estuarino, provocando mortandade da ictiofauna, crustáceos e moluscos, desequilibrando os sistemas ecológico e socioeconômico e afetando as populações que subsistem desses recursos. 


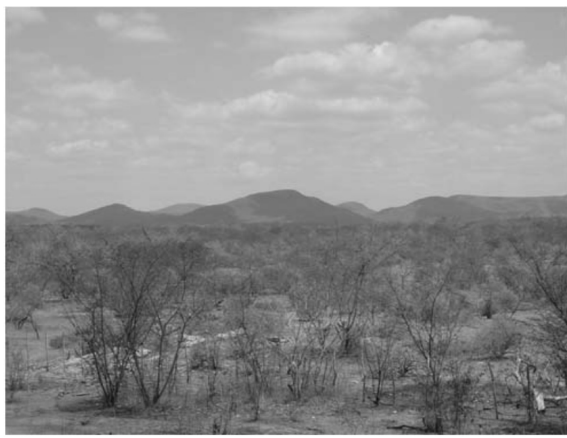

Fig. 02 - Vertente Ocidental da Serra do Machado e Sertões da Depressão Periférica do Centro-Norte do Ceará.

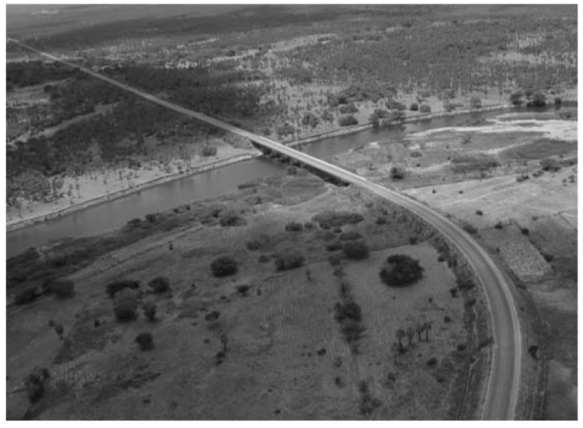

Fig. 03 - Planície fluvial do Rio Acaraú: divisa os Municípios de Cruz e Acaraú.

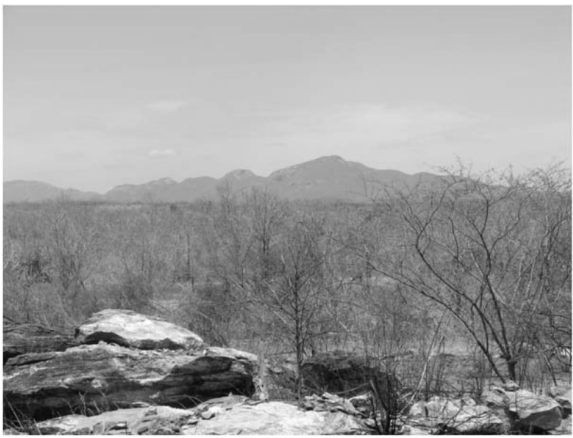

Fig 04 - Afloramentos rochosos. Maciço Residual das Serras das Matas.

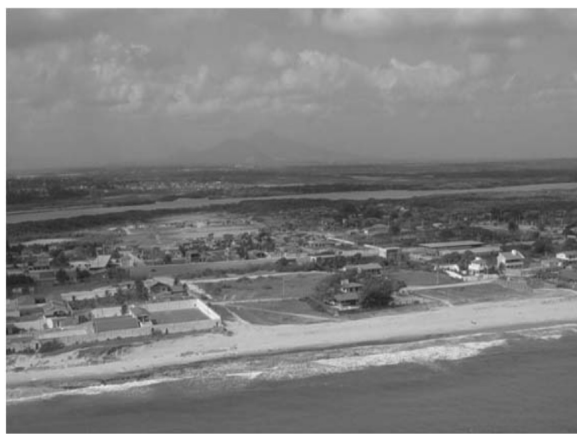

Fig. 05 - Vista aérea da Planície litorânea da Bacia do Acaraú: faixa de praia e planície flúvio-marinha

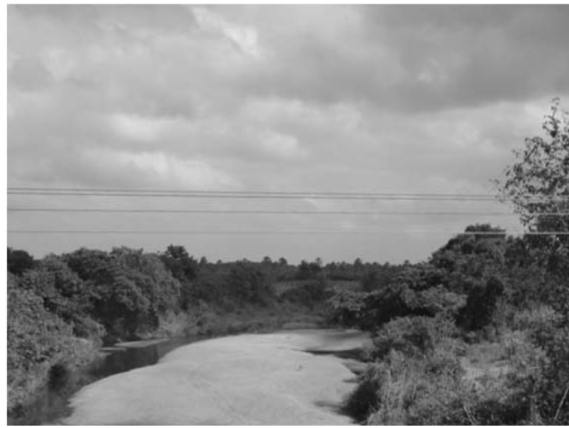

Fig. 06 - Planície Fluvial do rio Groaíras: principal afluente do rio Acaraú.

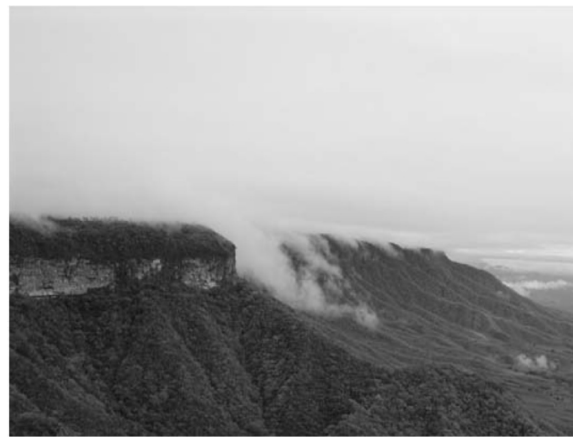

Fig. 07 - Front Central da Cuesta da Ibiapaba, exibindo a cornija arenítica sobreposta ao embasamento cristalino dissecado em cristas 
Os desmatamentos aceleram a eutrofização. Os processos erosivos dilapidam as heranças ambientais registradas nas paisagens, produzindo assoreamento dos fundos de vales, desarticulando o ciclo hidrológico e impactando a biodiversidade.

Os problemas ambientais oriundos do turismo têm sua gênese na inserção turística do litoral norte cearense em nível doméstico e internacional, preconizado pelo PRODETUR-CE. Ocorrem mudanças estruturais nas formas de produção, no mosaico paisagístico, nas formas de uso e ocupação da terra, deflagrando-se processos de desterritorialização da população nativa e conflitos de uso pelos recursos naturais. Investimentos em capitais fixos sobrepõem o capital natural dos ecossistemas, sub-valorizando o valor de uso, em detrimento do valor de troca em prol dos mercados. Neste caso, as paisagens litorâneas, em seus aspectos físicos e possibilidades de instalações de infra-estrutura hoteleira são destacados como mercadoria necessária ao desenvolvimento do setor.

O Estado, enquanto principal agente transformador do espaço, neste caso prioriza as políticas direcionadas ao turismo, com subsídios para (re) ordenação dos espaços, preferencialmente para a perspectiva de setores privados da economia. Os principais efeitos resultantes do não planejamento ambiental nesta atividade precisam ser destacados como alerta à reorientação das atividades, uma vez que as áreas preferenciais ao seu desenvolvimento são de alta fragilidade e vulnerabilidade ambiental. Assim, ocorre uma ocupação desordenada do solo, pela especulação imobiliária supervalorizando-o desrespeitando as normas e as leis ambientais, afetando principalmente os recursos hídricos. Os espaços públicos, como os terrenos de marinha, são apropriados para uso privado. A falta de saneamento básico e ruptura da dinâmica natural do litoral são outros problemas ambientais emergentes.

A perda da cultura pesqueira e marisqueira é uma violenta realidade, que ao lado de loteamentos, muitas vezes por grilagem, afetam a história dos povos locais. A compactação e/ou a criação artificial de solo com os loteamentos e construção de residências fixas ou segundas residências, também, impedem a mobilização de sedimentos, reduz o aporte transportado pelo rio para o mar desbalanceando a dinâmica costeira. Inclusive, podendo afetar o potencial hidrogeológico dos aqüíferos costeiros, que são as maiores reservas de águas subterrâneas de toda a bacia.

Com os problemas provenientes da produção agropecuária, por uma inadequação ou inexistência tecnológica, ou pelo uso intensivo, a biodiver- 
sidade é degradada. O descontrole de pragas e doenças, a perda da qualidade biológica, e a contaminação por insumos da agricultura, dos alimentos e do homem, além do próprio comprometimento da agricultura comprovando a vulnerabilidade deste setor econômico, vão se tornando comuns e corriqueiros. A irrigação, por exemplo, usada indiscriminadamente incorpora fertilizantes ao lençol freático, cursos fluviais e aos produtos cultivados. Os desmatamentos desordenados para o desenvolvimento da agropecuária quase sempre são acompanhados de ablação dos horizontes orgânicos dos solos, empobrecimento bioquímico e intensificação do assoreamento dos leitos fluviais. A substituição da base produtiva agrária pela industrial, paulatinamente, vem expropriando pequenos produtores, dificultando sua reprodução enquanto força de trabalho, quase que liquidando sua já débil força competitiva nos mercados econômicos. Dificulta-se até mesmo a sobrevivência da agricultura familiar.

No que tange à água, recurso natural renovável, porém exaurível, é impactada por ações socioeconômicas que lhe confere degradabilidade, reduzindo-lhe a quantidade utilizável em intervalos espaço-temporais freqüentemente mais curtos. As formas de utilização da água, ao contrário do que ocorre com a grande maioria de outros recursos naturais que desaparecem com o uso, geram modificações sensíveis em seus aspectos qualiquantitativos por meio da poluição e barramentos dos recursos hídricos. A poluição dos recursos hídricos está relacionada a pelo menos alguns vetores principais, a saber: esgotos domésticos e águas urbanas de escoamento superficial, águas servidas das atividades agropecuárias - incluindo-se a irrigação e a carcinicultura -, efluentes industriais, deficiência ou inexistência da coleta sistemática do lixo e sua disposição adequada.

Além de afetar o poder de resiliência da água, elemento essencial à vida, estes tipos de poluição podem provocar o aumento de incidência de doenças de veiculação hídrica, tencionando a relação estreita entre água e saúde pública. Comumente é elevado o teor de matéria orgânica nos lençóis subterrâneos e coleções d'água de superfície, tornando a qualidade da água imprópria para usos múltiplos, salinização dos corpos hídricos, só para citar os mais relevantes depreciadores. Devido aos problemas sanitários na bacia, às temperaturas elevadas e às vicissitudes de um balanço hídrico deficiente, associado à carência de educação ambiental e hábitos da população, as chances de surgimento de enfermidades vinculadas à água exigem maiores cuidados pelas autoridades competentes. 
Quanto ao barramento de cursos d'água, ocorre absurdamente sem suporte legal, privatizando as águas, um bem público de primeira necessidade. Nesta trajetória, a dinâmica do ciclo hidrológico altera tanto o volume d'água que seria infiltrado, como o aumento do escoamento superficial e evaporação. Isto modifica in input de água na bacia, interfere nas interações sistêmicas do balanço de energia, matéria e informação, comprometendo a geodinâmica e a renovabilidade hídrica.

Compiscuamente, a poluição e barramento dos recursos hídricos potencializam os conflitos decorrentes do uso e ocupação da terra, podendo ocorrer usos potencialmente competitivos pela a água, usos complementares, usos que competem entre si, ditos vinculados e competitivos, e usos concomitantemente complementares dependentes e competitivos. Sendo que conflitos sobre os uso doméstico $\mathrm{x}$ público $\mathrm{x}$ comercial $\mathrm{x}$ agropecuário $\mathrm{x}$ industrial e agroindustrial x turismo e lazer x conservação compulsória x especial (combates a incêndios, instalações desportivas, estações rodoviárias etc), são corriqueiros.

Com o desmatamento desenfreado e a redução da biodiversidade há exaustão dos recursos hídricos e comprometimento das formas de vida. A retirada da vegetação nativa provoca diminuição de habitats naturais, ocasionando o desaparecimento de espécies vegetais e animais, sobretudo de mamíferos, invasão de espécies vegetais de baixo valor comercial e a homogeneização dos ecossistemas. A destruição de refúgios, a escassez de alimentos e a pesca predatória prejudicam a fauna. Os desmatamentos desordenados não respeitaram as condições das relações biocêntricas entre espécies da flora e fauna com seu entorno. Dessa forma, há empobrecimento ecológico, perda dos mecanismos de autodefesa e aumento da vulnerabilidade aos impactos negativos e às pragas. Os principais problemas ligados à atividade industrial se dão por operações, muitas vezes, sem maior rigor técnico, em descumprimento à legislação ambiental e sob negligências ambientais das empresas. Os efeitos externalizados ao meio ambiente ocorrem pela: emissão de gases tóxicos, não tratamento de esgotos, mau acondicionamento dos resíduos sólidos, remoção do substrato das unidades morfopedológicas, intensificação dos processos de solifluxão, alteração da drenagem, assoreamento, turbidez das águas, poluição, destruição e fragmentação dos ecossistemas e modificações estéticas da paisagem.

Além dos já referidos problemas vinculados a alguns setores industriais, cabe ao setor mineral a outra grande parcela de prejuízos às condições ambientais. A necessidade por saneamento básico e habitação, vem aumen- 
tando a demanda por matérias-primas ordinárias, os denominados agregados. Assim, a extração e lavra clandestina destes produtos vêm provocando impactos negativos, sobretudo nas áreas do litoral (dunas, praias), tabuleiros costeiros, e nos vales fluviais conforme foi observado em vários trechos do rio Acaraú e tributários principais, como Groaíras, Macacos, Jacurutú e Jaibaras. Com uma operacionalidade complexa, a mineração envolve componentes da terra, da água e do ar. Origina intensos e diversos efeitos sobre o meio ambiente, podendo causar danos irreparáveis.

\section{Categorias espaciais de ambientes naturais}

Os sistemas ambientais são classificados e hierarquizados de acordo com suas dimensões, e conforme suas características de origem e de evolução. Visa-se, além disso, conhecer aspectos importantes dos processos evolutivos da região e suas potencialidades e limitações geoambientais, frente às formas de uso/ocupação e desertificação.

Considerando a diversidade interna dos geossistemas, são delimitadas as unidades elementares contidas em um mesmo sistema de relações, destacando-se, desta forma, os geofácies. Sob esse aspecto, a concepção de paisagem assume significado para a delimitação das subunidades, em função da exposição de padrões uniformes ou relativamente homogêneos. É nessa perspectiva que os fatores geoambientais e os padrões de ocupação humana tendem a constituir dados instáveis onde se torna importante a acentuada variação tempo-espacial das paisagens. Assim, via de regra, os geossistemas são formados por paisagens diferentes e, apenas os geofácies, como subunidades internas dos geossistemas, apresentam maior uniformidade.

Para delimitação dos geossistemas/geofácies da bacia, considerou-se a análise geomorfológica como elemento de importância fundamental. Os limites do relevo e as feições do modelado são mais facilmente identificados e passíveis de delimitação mais rigorosa e precisa. Deve-se reconhecer, além disso, que a compartimentação geomorfológica deriva da herança da evolução geoambiental, pelo menos Tércio-Quaternária. Como tal, cada compartimento tende a ter padrões de drenagem superficial, arranjamentos típicos dos solos e características singulares quanto aos aspectos fitofisionômicos e, por conseqüência, os padrões de ocupação são também influenciados.

A diversificação da paisagem depende da variedade de combinações entre os componentes geoambientais. As serras e as planícies são áreas mais 
densamente povoadas e de vida agrária mais intensa. Na faixa pré-litorânea, não obstante a melhoria das condições climáticas, os solos (Neossolos Quartzarênicos) são em grande parte dotados de baixa fertilidade, o que dificulta uma maior diversificação dos sistemas de produção. Os sertões, aparentemente mais homogêneos, possuem também uma significativa diversificação geo-ecológica.

A ocorrência de espaços diferenciados, não chega, assim, a impor mudanças agudas quanto aos processos de utilização da terra. O que se nota, de modo indistinto, é a persistência de métodos rudimentares, desarmônicos com as condições de recursos naturais disponíveis. A homogeneidade do espaço estudado é assim vinculada à pobreza econômica e não propriamente às condições estritamente naturais. É certo, porém que as limitações impostas pelas potencialidades ecológicas têm significado destacável para justificar a debilidade e vulnerabilidade das atividades econômicas, muito dependentes da irregularidade pluviométrica do semi-árido.

Sob o aspecto de uso/ocupação da terra, a bacia do Acaraú tem no setor primário da economia, suporte fundamental, através de uma participação expressiva na formação da renda ou por representar a principal parcela do emprego regional. Esta situação, cabe salientar, vem se mantendo inalterada ao longo dos anos. Nesse particular, as limitações naturais têm papéis importantes para justificar um ritmo de crescimento que longe está de atingir o desejado. A área dos sertões é, por excelência, o domínio do criatório extensivo, do agro-extrativismo e da pequena lavoura de subsistência. Esse complexo representa o mais importante sistema de produção regional. Evidenciam-se mudanças apenas no tocante à combinação de fatores, pois ora há primazia da pecuária, ora da atividade agro-extrativista e de subsistência.

Os principais perímetros irrigados da bacia se situam no Araras Norte, Baixo Acaraú, dentre outros de menor expressão. O de maior expressão e em fase de implementação é o perímetro do Baixo Acaraú, que deve ocupar áreas da planície fluvial e dos tabuleiros pré-litorâneos. Desta forma, a Tabela a seguir apresenta a hierarquia espacial dos sistemas ambientais da bacia do rio Acaraú. Nela é possível examinar os principais atributos dos recursos naturais. 


\begin{tabular}{|c|c|c|c|}
\hline & 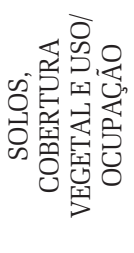 & 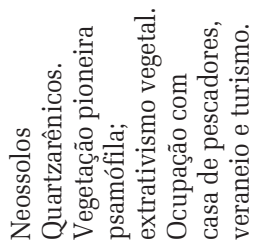 & 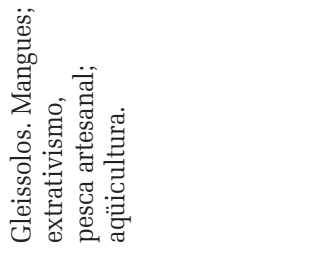 \\
\hline & 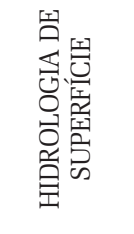 & 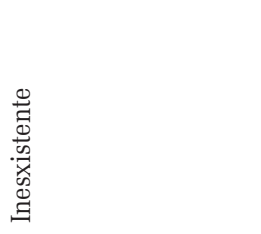 & 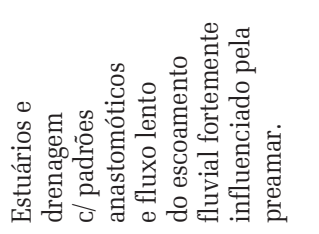 \\
\hline & 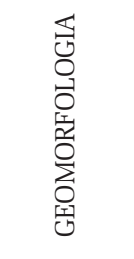 & 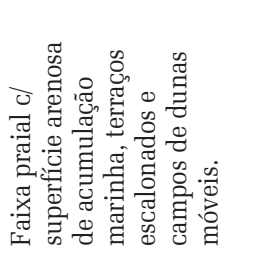 & 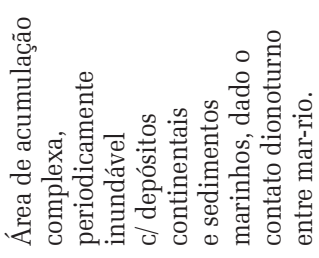 \\
\hline & ○崖 & 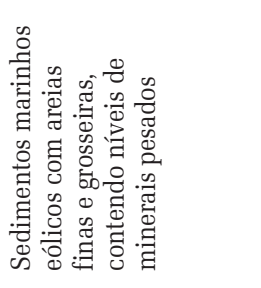 & 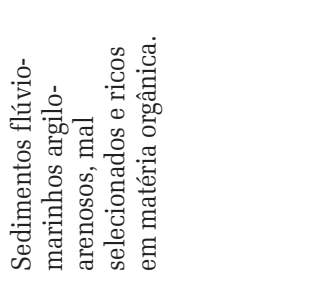 \\
\hline \multirow{3}{*}{ 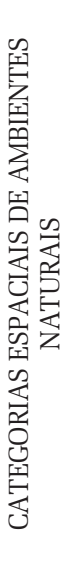 } & 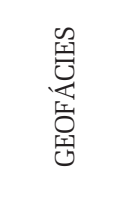 & 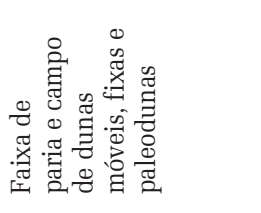 & 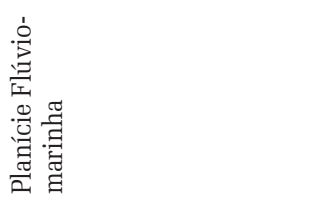 \\
\hline & 总 & \multicolumn{2}{|l|}{ 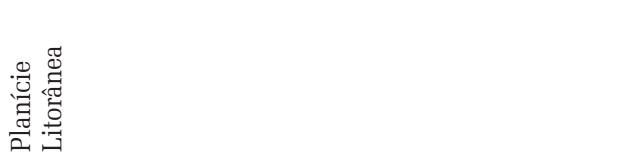 } \\
\hline & 员媱 & \multicolumn{2}{|l|}{ 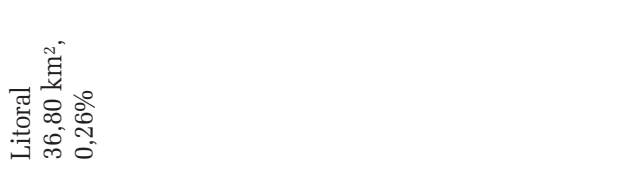 } \\
\hline
\end{tabular}




\begin{tabular}{|c|c|c|}
\hline 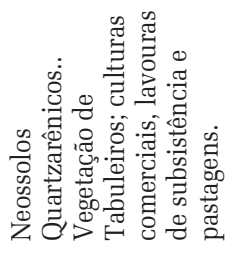 & 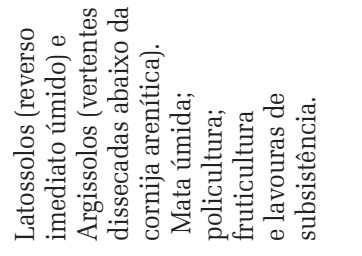 & 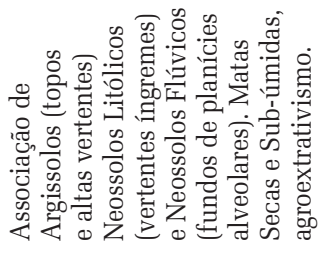 \\
\hline 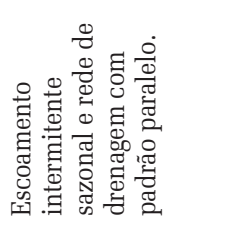 & 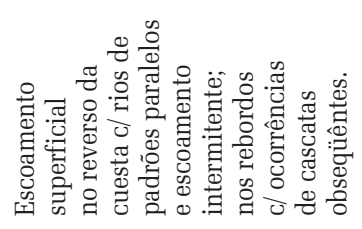 & 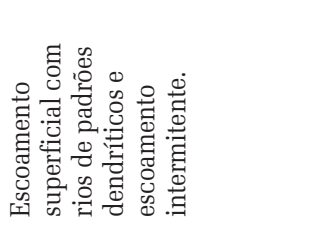 \\
\hline 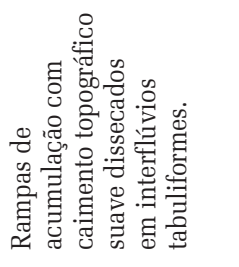 & 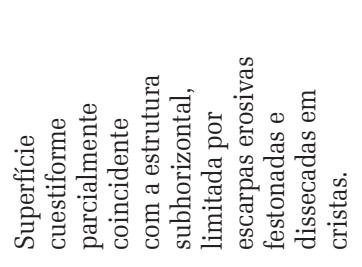 & 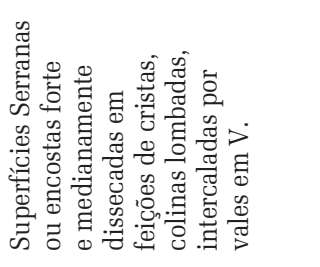 \\
\hline 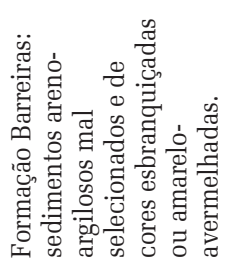 & 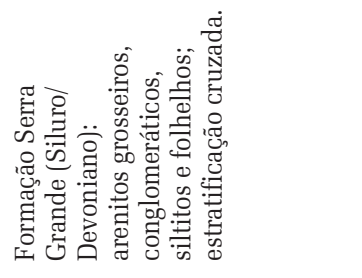 & 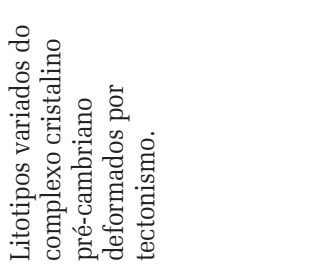 \\
\hline 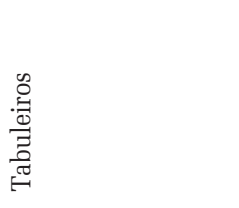 & 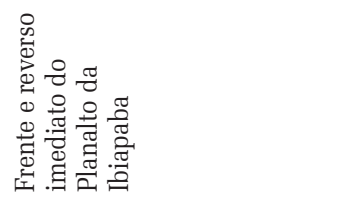 & 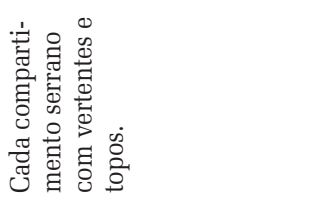 \\
\hline 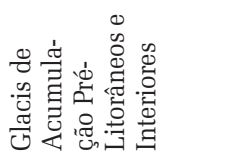 & 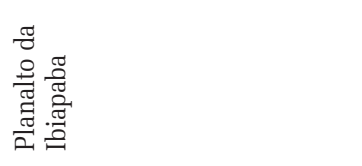 & 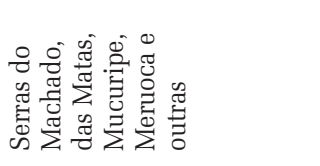 \\
\hline 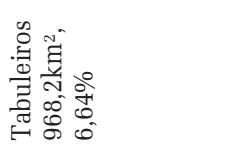 & 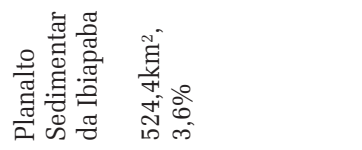 & 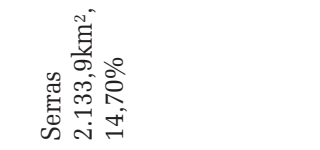 \\
\hline
\end{tabular}




\begin{tabular}{|c|c|}
\hline 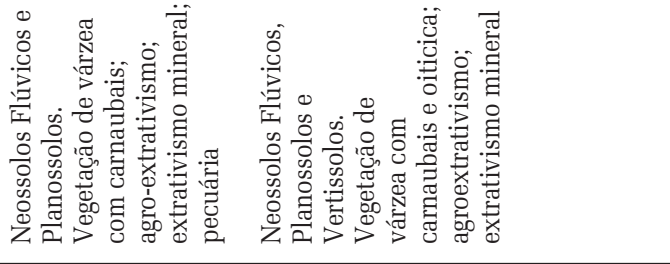 & 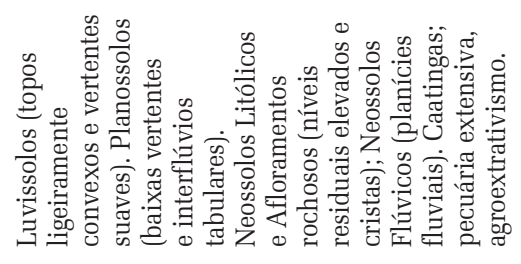 \\
\hline 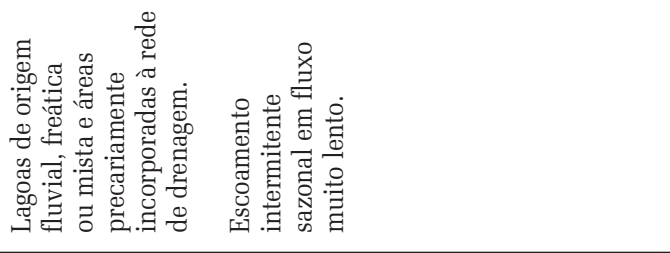 & 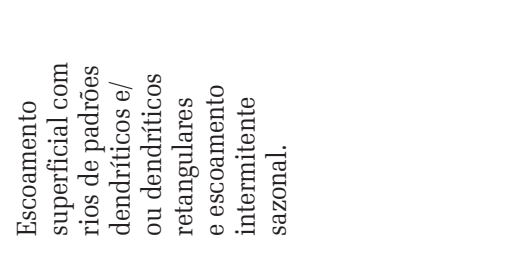 \\
\hline 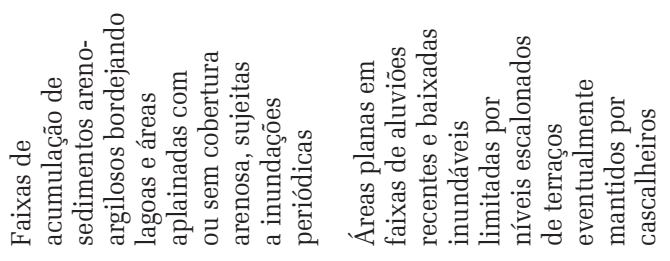 & 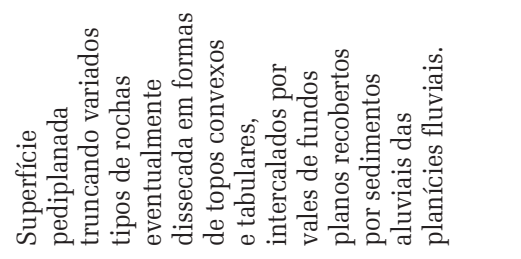 \\
\hline 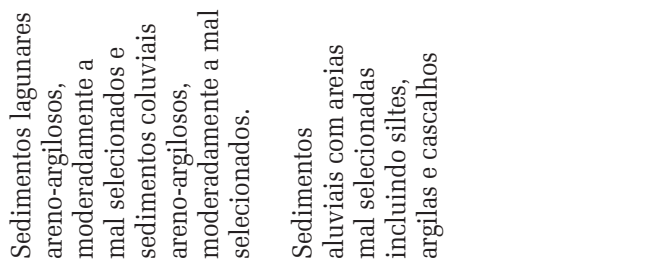 & 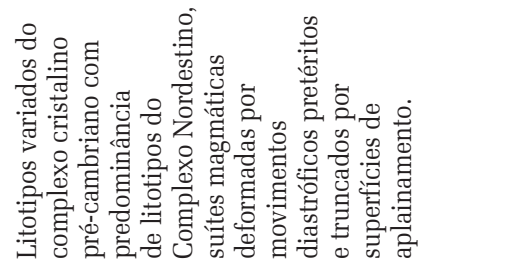 \\
\hline 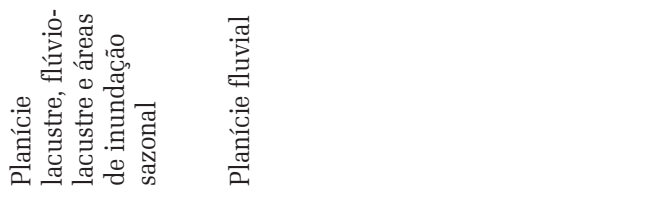 & 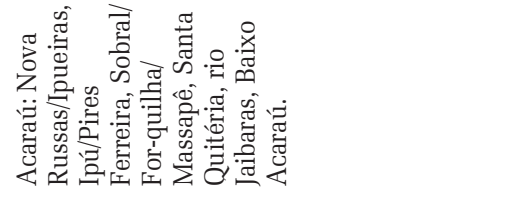 \\
\hline 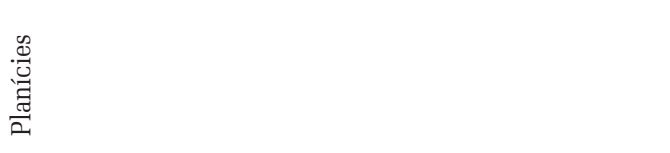 & 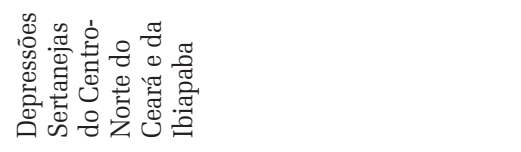 \\
\hline 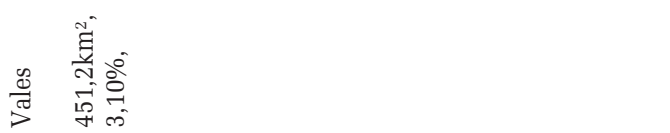 & 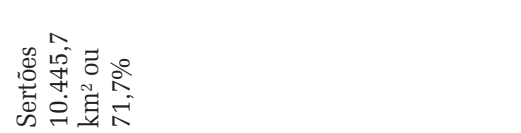 \\
\hline
\end{tabular}


Adaptado de Souza (2000), Nascimento et al., (2007), ratificado por trabalhos de sensores remotos e de campo

\section{Considerações finais}

Como visto, o diagnóstico do meio físico apresenta uma proposta de síntese da Compartimentação Geoambiental através de quadros sinópticos. Esta proposta foi apoiada na análise temática de variáveis ambientais e nas relações mútuas entre as mesmas. Portanto, foi priorizada a visão de totalidade para a caracterização das unidades geossistêmicas. A organização das informações geoambientais seguiu a hierarquia espacial taxonômica contida nas unidades inferiores propostas por Bertrand (1969), priorizando-se em função das ordens de grandeza, os geossistemas e geofácies.

Contudo, na preparação da discussão dos aspectos atinentes à compartimentação geoambiental, seleciona-se as características dos principais atributos ambientais. Elas serviram de base para indicar condições favoráveis ou limitantes para o uso e ocupação da bacia do rio Acaraú, considerando-se as vicissitudes da semi-aridez regional como subsídio à organização territorial que venha a nortear as políticas de uso e ocupação da terra. A identificação e delimitação dos sistemas naturais resultaram do agrupamento de áreas dotadas de condições específicas quanto às relações mútuas entre os fatores do potencial ecológico (fatores abióticos) e os da exploração biológica, compostos essencialmente pelo mosaico de solos e pela cobertura vegetal. Esse mapa, organizado através da interpretação das imagens de sensoriamento remoto do TM LANDSAT 5 e LANDSAT 7 ETM+, de imagens de radar, da análise do acervo cartográfico temático oriundo de levantamentos sistemáticos dos recursos naturais do Ceará, é de importância fundamental para o conhecimento e avaliação da área de estudo. Ele fornece os requisitos considerados imprescindíveis para definir a qualidade dos atributos naturais em termos de potencialidades e limitações, tendo em vista suas repercussões na qualidade ambiental.

\section{Referências}

AB’SABER, A. N. O domínio morfoclimático semi-árido das Caatingas Brasileiras. In Geomorfologia. V.43. São Paulo, 1974. 
BERTRAND, G. Paisagem e geografia física global: esboço metodológico. In: Caderno de Ciências da Terra, v.13, São Paulo, 1969. p. 1-21.

MMA. Programa Zoneamento Ecológico-Econômico: diretrizes metodológicas para o zoneamento ecológico-econômico do Brasil. Ministério do Meio Ambiente - Secretaria de Políticas para o Desenvolvimento Sustentável. Brasília - DF, 2001.

NASCIMENTO, Flávio R. do. Recursos Naturais e Desenvolvimento Sustentável: Subsídios ao gerenciamento geoambiental na Sub-Bacia do Baixo Pacoti - CE. (Dissertação de Mestrado), 154p. UECE: Fortaleza, 2003.

. Cunha, Sandra B. da e Rosa, Morsyleide Freitas. Desertificação em bacias hidrográficas semi-áridas no Nordeste brasileiro - estado do Ceará. In: Bezerra, Amélia C. A., Gonçalves, Cláudio U.: Nascimento, Flávio R. do; Arrais, Tadeu A (Organizadores). Itinerários Geográficos. Niterói: Eduff, 2007. p. 281-311

SOUZA, M. J. N. de. Bases naturais e esboço do zoneamento geoambiental do estado do Ceará. In: Compartimentação territorial e gestão regional do Ceará, Parte I. Universidade Estadual do Ceará - UECE. Editora FUNECE. Fortaleza, 2000.

SOUZA, M. J. N. de. Contribuição ao estudo das unidades morfo-estruturais do estado do Ceará. In: Revista de Geologia, v.1, Edições Universidade Federal do Ceará. Fortaleza, 1988. p.73-91.

SOUZA, M. J. N. de. Limitações geoambientais ao desenvolvimento sustentável do semi-árido brasileiro. Publicaciones Universitat de Barcelona. Barcelona, 2003.

TRICART, J. Ecodinâmica. FIBGE/SUPREN. Rio de Janeiro, 1977.

\section{Fonte}

1 O presente artigo é parte integrante do projeto Análise geoambiental e mapeamento d as áreas degradadas susceptíveis à desertificação na Bacia Hidrográfica do Acaraú (CE): Geoprocessamento aplicado ao manejo e conservação dos recursos naturais. Por isso, agradecemos ao Banco do Nordeste do Brasil pelo financiamento da pesquisa em nome da equipe técnica.

Flávio Rodrigues do Nascimento - Professor da Universidade Federal Fluminense

Sandra Batista da Cunha - Pesquisadora CNPq, Universidade Federal Fluminense - Campus da Praia Vermelha

Marços José de Souza - Pesquisador da Universidade Estado do Ceará

Maria Lúcia Brito da Cruz - Mestre em Desenvolvimento e Meio Ambiente. Professora da UECE 